\title{
Characterization of Bio-composite Apatite/Chitosan Cement and its Antibacterial Activity
}

\author{
N. MONCIF ${ }^{1 \star}$, EL. H. GOURRI ${ }^{1}$, AB. A. ELOUAHLI ${ }^{1}$, M. EZZAHMOULY ${ }^{1,4}$, \\ K. NAYME ${ }^{2,3}$, M. TIMINOUNI ${ }^{2,3}$ and Z. HATIM ${ }^{1}$ \\ 'Biomaterials and Electrochemistry Team. Chouaib Doukkali University, El-Jadida-Morocco. \\ ${ }^{2}$ Molecular Bacteriology Laboratory, Pasteur Institute of Morocco, Casablanca, Morocco. \\ ${ }^{3}$ Microbiology Laboratory, Faculty of Medicine and Pharmacy, Casablanca, Morocco. \\ ${ }^{4}$ Laroseri laboratory, Computer Science Department, Chouaïb Doukkali University, \\ El-Jadida-Morocco. \\ ${ }^{*}$ Corresponding author E-mail: dr.nawal2013@gmail.com
}

http://dx.doi.org/10.13005/ojc/340408

(Received: June 27, 2018; Accepted: July 31, 2018)

\begin{abstract}
In this work, we report the physico-chemical properties and antibacterial activity of apatite/chitosan composite cements. The biocomposite was prepared by reaction between dihydrated dicalcium phosphate and calcium hydroxide in the presence of chitosan. The characterization of cement was carried out by Infrared Spectroscopy, X-ray diffraction, Transmission Electron Microscopy and X-ray Scanner with computational image processing. The results show that the setting of the paste is due to the formation of a hydrated tri-calcium phosphate that evolves into a hard calcium-apatite. In the presence of chitosan, the fastness of setting time is attributed to the precipitation of chitosan that strengthens the cohesion between grains. The formed complex evolves into hard Apatite-chitosan composite. In an induced bone defect, the hard composite shows radiopaque homogenous microstructure and intimate contact bone/implant. The antibacterial tests of hard cements show a significant reduction in Staphylococci bacterial growth on the surface of composite grains. This reduction is highly dependent on the type of bacteria, and the percentage of the added antibacterial agent. Bio-composite cement shows total inhibition of Staphylococci aureus and low resistance to Staphylococci epidermidis. The apatite/chitosan composite prepared by the way of cements can have interesting applications as bone substitute material.
\end{abstract}

Keywords: Bio-composite, Interfaces, Crystal growth, Phase transitions, antibacterial activity.

\section{INTRODUCTION}

Calcium-phosphate compounds, as bone substitute materials have a large place in clinical applications ${ }^{1}$. Today, the calcium phosphate cements receive much interest for their various properties such as their biocompatibility and their ease introduction by the mini-invasive surgical techniques ${ }^{2-6}$. However public health problems are present during the medical application with the risk of infection by pathogenic 
bacteria, in particular staphylococci which have a high affinity for living tissues 7,8 . The inflammation in the implant surrounding tissue eventually leads to the loss of the implant. To meet the growing demand for improvement of quality and safety of biomaterials, the development of antibacterial cement is in strong expanding these last year's ${ }^{9}$. At first, orthopedic surgeons have taken in consideration this risk of infection by the introduction of intravenous antibiotics during the implantation ${ }^{10,11}$. Despite these precautions, it was reported that in each year, the infections were the direct cause of many deaths. Therefore, many studies have been conducted on the direct introduction of antibiotics in bone substitutes and particularly in calcium phosphate cements, such as gentamicin ${ }^{12}$ cephalexin ${ }^{13}$ vancomycin ${ }^{14,15}$, or silver ${ }^{16,20}$. Their use has treated the infection but their high cost and bacterial resistance to the drug limits their effectiveness. Another type of organic and natural antibacterial agent, namely the chitosan which is known to be biocompatible and biodegradable. This polymer is widely used in the biomedical field such as tissue engineering and is reported to stimulate the host immune system against viral and bacterial infections $\mathbf{s}^{17-20}$. Chitosan is a polymer obtained by deacetylation of chitin which is the main component of the wall of crustaceans. Its chemical formula is linear and composed of units of $\mathrm{N}$-acetyl-D-glucosamine and $\mathrm{D}$-glucosamine linked together by $\beta$ 1-4 bonds $\left(\left(\mathrm{C}_{8} \mathrm{H}_{13} \mathrm{NO}_{5}\right) \mathrm{n}\right)$. It can be developed into any shape and size, such as films, microspheres, nanoparticles, porous membranes and scaffolds. It is characterized by a degree of deacetylation (DD) and a molecular weight (MW). These parameters influence on its interesting properties ${ }^{21}$. In this study, the antibacterial activity of chitosan/apatite cement has been investigated. The composite past is prepared by mixing dehydrated dicalcium phosphate, calcium hydroxide, chitosan and some additives. The antibacterial tests are performed after the evolution for five days of cement paste prepared by varying the concentration of the chitosan in the liquid phase. The two selected bacteria are from the family Staphylococci namely aureus and epidermidis.

The effect of chitosan on the mechanical properties on calcium phosphate biomaterials have been shown and discussed in the literature ${ }^{18,22}$, but the effect of chitosan on the mechanism reaction to the setting and hardening of cement has been a little studied ${ }^{23}$. The purpose of this work is to study the effect of the chitosan on the physicochemical evolution of the cement and the evaluation of the antibacterial activity of apatite/chitosan cement. Microstructure and location of bio-composite cement inside a cortical bone cavity have been evaluated. The antibacterial study was conducted in the Molecular Bacteriology Laboratory of Pasteur Institute of Morocco.

\section{MATERIALS AND METHOD}

All the chemicals used in the study were obtained from analytical grade (Sigma-Aldrich). $\mathrm{CaHPO}_{4}, 2 \mathrm{H}_{2} \mathrm{O}$ reactive powder was synthesized at $25^{\circ} \mathrm{C}$ and $\mathrm{pH}=4.8$, by rapid reaction between $\mathrm{CaCO}_{3}$ and $\mathrm{H}_{3} \mathrm{PO}_{4}$ using a vigorous stirring. $\mathrm{Ca}(\mathrm{OH})_{2}$ reactive powder is prepared by hydratation of calcium oxide in double distilled water. The calcium oxide is prepared by calcination of $\mathrm{CaCO}_{3}$ at $900^{\circ} \mathrm{C}$ for 12 hours.

\section{Chitosan preparation}

As a first step, chitin is extracted from carapaces of prawns, washed, crushed and then demineralized using repeated baths of diluted chloride acid $(0.2 \mathrm{~N})$ and deproteinized by repeated baths of diluted hydroxide sodium $(0.5 \mathrm{~N})$. Chitin product is treated two times with sodium hydroxide solution $(45 \%, v / v)$ at $100^{\circ} \mathrm{C}$ for $4 \mathrm{~h}$ to obtain chitosan. The obtained flakes were then purified by i) solubilisation in the acetic acid solution $(2 \%, v / v)$, ii) precipitation at $\mathrm{pH}=8$ in hydroxide sodium solution, iii) Intensive washing with deionized water and then with a glycerol / water mixture $(1 \%, v / v)$. The obtained powder is then dried at $45^{\circ} \mathrm{C}$ and preserved at $5^{\circ} \mathrm{C}$.

\section{Cement paste and cement disk preparation}

Cement paste is prepared by mixing liquid and solid phases with a liquid to powder ratio (L/P) of $0.55 \mathrm{ml} \mathrm{g}^{-1}$. Solid phase is composed by mixture of $\mathrm{CaHPO}_{4}, 2 \mathrm{H}_{2} \mathrm{O}$ (DCPD) and $\mathrm{Ca}(\mathrm{OH})_{2}$ powders with molar ratio of $\mathrm{Ca} / \mathrm{P}=1.65 \pm 0.02(\mathrm{Ca} / \mathrm{P}=1.67$ is the molar ratio of the stoichiometric hydroxyapatite $\left.\left(\mathrm{Ca}_{10}\left(\mathrm{PO}_{4}\right)_{6}(\mathrm{OH})_{2}\right)\right)$. Xanthan is added to the solid phase with concentration of $3 \%$ (mass percentages compared to formed apatite). Liquide phase is prepared by dissolution of chitosan in lactic acid 
solution $(1 \% \mathrm{v} / \mathrm{v})$. The powder of chitosan is adjusted to $1 \%, 2 \%$ and $3.5 \%$ mass percentages compared to formed apatite. The cement paste is obtained after mixing liquid and solid phases in a mortar with a spatula for two minutes. Cement disks (10 \pm 0.1 $\mathrm{mm}$ and $5 \pm 0.1 \mathrm{~mm}$ as thickness diameters) are prepared by filling silicone mold with the prepared paste. The parts are then placed in water at $37^{\circ} \mathrm{C}$ for five days. After drying, disks are removed from the mold and sterilized by UV.

\section{Antibacterial tests}

To define the effect of chitosan incorporation, the antibacterial activity is investigated considering the ability of staphylococci to adhere and colonize cement surfaces. S. aureus and $S$. epidermidis (Pasteur Institute Collection, Casablanca, Morocco) are grown in 24-well microplates containing disk of each cement.

One disk of each cement is placed inside the wells of a 24-well plate that contained $2 \mathrm{~cm}^{3}$ of culture medium modified biofilm broths MBB as previously described.

The model selected considering that the composition of MBB and the renewal of the medium promotes adherent but not planktonic cell growth with a biofilm structure.

After initial inoculation with $102 \mathrm{CFU}$, the MBB medium is renewed at 2, 4, 6, 20, 24 and $48 \mathrm{~h}$ for $S$. aureus and at 6, 20, 24 and $48 \mathrm{~h}$ for $S$. epidermidis incubation at $37^{\circ} \mathrm{C}$ after two gentle rinses with sterilized distilled water $\left(2 \mathrm{~cm}^{3}\right)$. Biofilms are grown for $72 \mathrm{~h}$. The wells and cement pellets are then rinsed and $2 \mathrm{~cm}^{3}$ of distilled water are added. Adherent bacteria are removed by scraping with a sterile spatula and CFU numeration is performed on the solution. The entire suspension is directly inoculated in trypcase soy agar (Biomérieux, France) or tenfold diluted before adding $100 \mu \mathrm{L}$ in trypcase soy agar (incubation 24 to $48 \mathrm{~h}$ at $37^{\circ} \mathrm{C}$ ). Each experiment is performed three times to check the reproducibility of this study.

\section{Characterization}

The degree of deacetylation (DD) of the chitosan is calculated from ${ }^{1} \mathrm{HRMN}$ and the average molecular weight is determined by viscometer
(ViscoClock). Ion traces have been analyzed by atomic emission spectrophotometer, argon plasma and inductive coupling (ICPAES) (Thermo Jarrel Ash Atom Scan16). Setting time of cement is measured with a Gilmore needle (Vicat) according to the C266-ASTM standard. Morphology, composition and structure are carried out during the setting and hardening of the cement prepared with and without chitosan. At the required moment of examination, a sample is collected, washed with ethanol, then frozen and characterized by Infrared Spectroscopy (IR) (PerkinEImer FTIR 1600), X-ray diffraction (RDX) ( (Siemens 5000, $\lambda \mathrm{Cu}=1,5408 \AA$ ) and Transmission Electron Microscope (TEM) (microscope JSM 6300 de JEOL, tension $15 \mathrm{kV}$ ). The biocomposite cement placed inside defect cortical bone is investigated by $\mathrm{X}$-ray Scanner technique using a high-resolution device (EasyTom XLduo). The computational image processing is applied on the reconstructed images; the obtained images are processed by filtering that can effectively remove noise and improve the description of the edges.

\section{RESULTS}

\section{Chitosan}

The degree of deacetylation of prepared chitosan is found to be close to $78 \pm 2 \%$, and the average molecular weight is $250.000 \mathrm{~g} / \mathrm{mol}$.

The purity of chitosan is a factor which affects not only the biological properties like immunogenicity or biodegradability, but also affects its solubility and stability. The presence of ion traces like $\mathrm{Mg}, \mathrm{Zn}, \mathrm{Ca}$...in prepared chitosan can also have an influence on the kinetics of the apatite formation ${ }^{24}$. 18 ions' traces have been analyzed and the results show that these ions are present with concentration less than 0,05wt\%.

\section{Apatite and apatite/chitosan cement}

After mixing the solid with liquid phase, in the presence as in the absence of chitosan, the components turn into a malleable paste that sets to a firm mass without disintegration after immersion in water at $37^{\circ} \mathrm{C}(\mathrm{pH}=6.5)$. A very good malleability is observed when the percentage of the chitosan is 3.5 wt. Setting and hardening times of the paste prepared with 0,1 , and 2 wt $\%$ of chitosan are similar. The paste sets at $45 \mathrm{~min}$. and hardened 
after 1 hour. For the cement prepared with 3.5 wt \% of chitosan, the paste sets at $30 \mathrm{~min}$. and hardened after $45 \mathrm{~min}$. In this study, we present the results of the characterization of cements prepared with 0 and $3.5 \mathrm{wt} \%$ of chitosan.

In Fig.1a, the XRD patterns of various samples taken during the evolution of the prepared paste without chitosan are shown. The X-Ray pattern of the paste taken 5 min. after mixing shows all diffraction peaks of DCPD listed in ICDD PDF (International center for diffraction Database) $\mathrm{n}^{\circ} 9007$. The diffraction pattern of the sample taken $48 \mathrm{~h}$ after mixing shows the formation of calcium-apatite phase identified by the presence of its characteristics peaks listed in ICDD PDF (International center for diffraction Database) $\left.n^{\circ} 9-432\right)$. In this sample, the presence of traces of
DCPD peaks has been noticed. The XRD pattern of the sample taken within five days of maturation indicates that the hard cement consists of poorly crystallized apatite.

The results of the analysis by IR spectroscopy (Fig. 1b) shows at $5 \mathrm{~min}$. and $48 \mathrm{~h}$, the presence of the characteristics bands of DCPD phase. The IR spectrum of the cement obtained after five days of mixing shows the formation of the apatite phase poorly crystallized easily identified by the presence of its characteristic bands: $v_{1} \mathrm{PO}_{4}$ (962 cm $\left.\mathrm{cm}^{-1}\right), v_{2} \mathrm{PO}_{4}\left(640 \mathrm{~cm}^{-1}\right), v_{3} \mathrm{PO}_{4}(1030-1100$ $\left.\mathrm{cm}^{-1}\right)$, and $v_{4} \mathrm{PO}_{4}\left(563-601 \mathrm{~cm}^{-1}\right)$. It can be seen the absence of the characteristic bands of the $-\mathrm{OH}$ group (630 and $3500 \mathrm{~cm}^{-1}$ ) and the presence of characteristics bands of carbonate group $\left(875 \mathrm{~cm}^{-1}\right.$, 1410 and $\left.1450 \mathrm{~cm}^{-1}\right)$. This indicates the evolution of the past to a carbonated apatite phase..$^{25}$
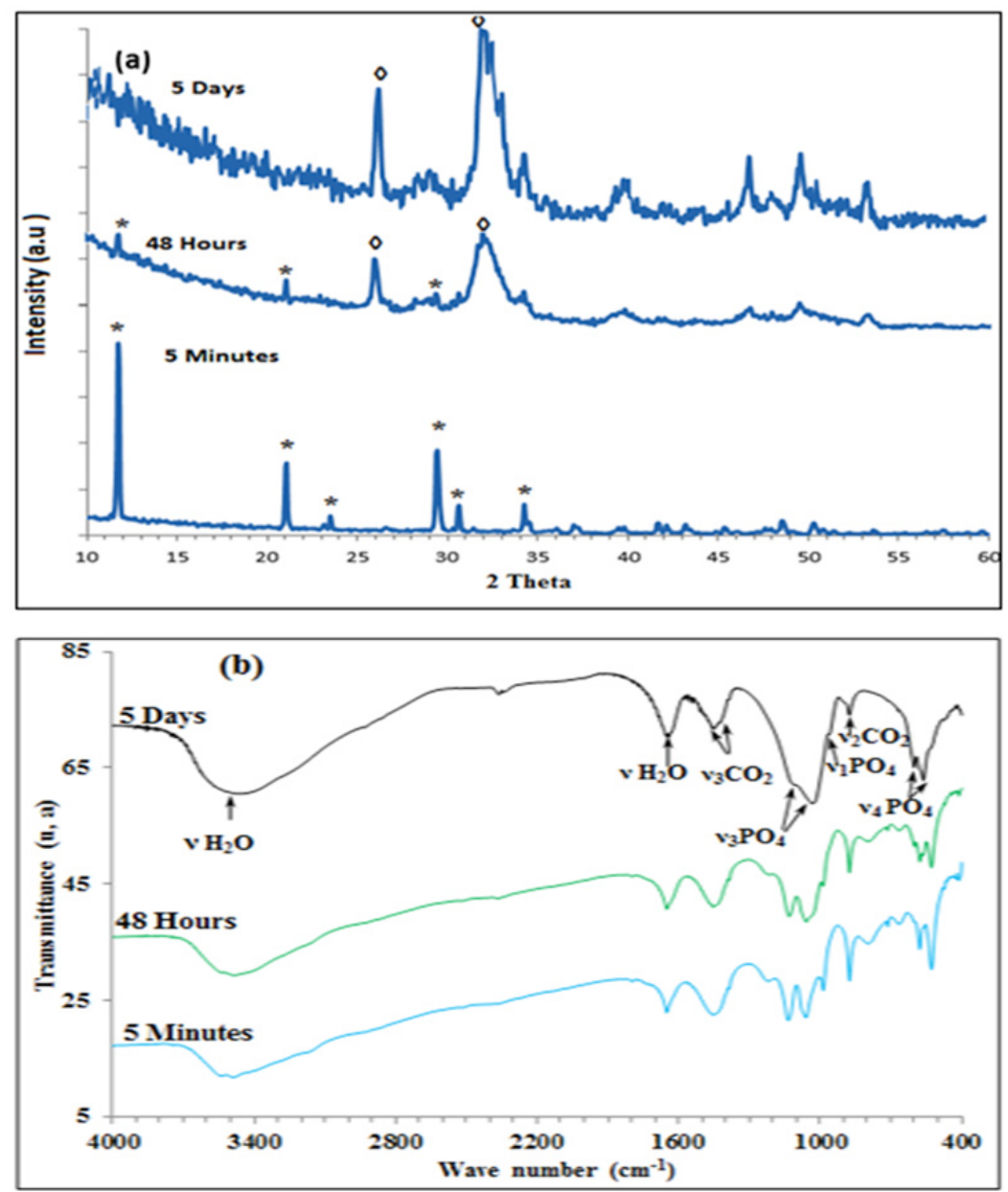

Fig. 1. X-Ray patterns (a) and IR spectrum (b) of the cement samples without chitosan after immersion in deionized water at $37^{\circ} \mathrm{C}: 5 \mathrm{~min} .48 \mathrm{~h} 5$ days. The main reflections of DCPD are indicated by $\left({ }^{\star}\right)$; The Calcium-apatite is indicated by $(\bullet)$ 
In Figs. $2 a$ and $2 b$ are shown, the XRD patterns and IR spectrums for various samples taken during the evolution of the cement prepared with $3.5 w t \%$ of chitosan. The results illustrate an evolution of the biocomposite comparable to that has been observed in cement without chitosan. As can be seen in Fig. 2a, the formation of the apatitic phase poorly crystallized and the disappearance of dicalcium phosphate phase is slightly delayed. The XRD pattern of the hardened cement (Fig. 2a) taken after five days of maturation, depicted as a poorly crystallized apatite phase. IR spectrum (Fig. 2b) of this sample shows only the characteristic bands of carbonated apatite phase.
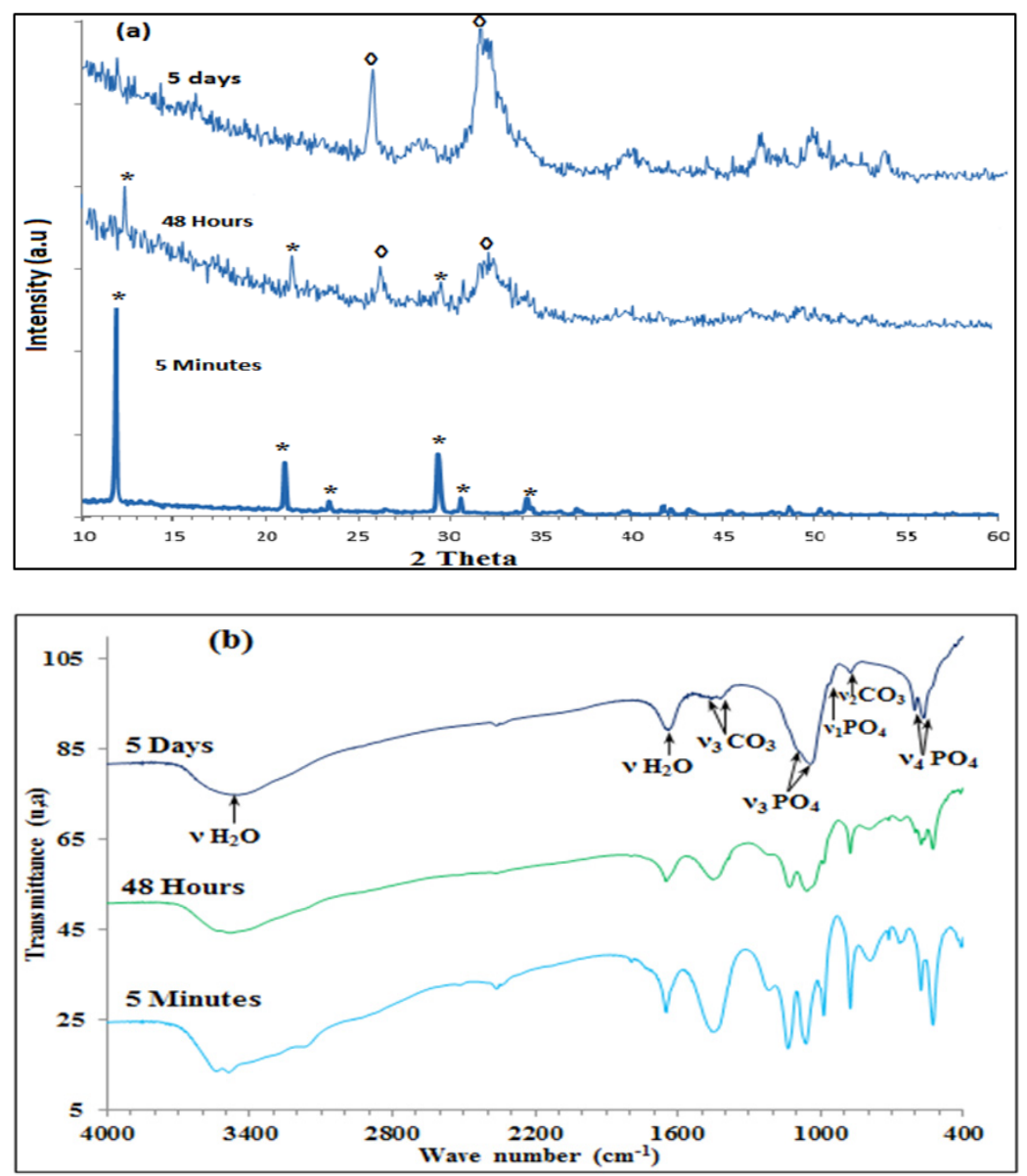

Fig. 2. X-Ray patterns (a) and IR spectrum (b) of the bio-composite cement with $3.5 \mathrm{wt} \%$ of chitosan after immersion in deionized water at $37^{\circ} \mathrm{C}: 5 \mathrm{~min} .48 \mathrm{~h}$ and 5 days. The main reflections of DCPD are indicated by $\left({ }^{*}\right)$; The Calcium-apatite is indicated by $(\bullet)$

Analyses by TEM (Fig. 3) show the microstructure of the two prepared cements after five days of maturation. The hard cements with and without chitosan are composed of calciumapatite, crystallized as needle-like entangled. The bio-composite cement shows the fine needles and spherical agglomerates.

$\mathrm{X}$-ray Scanner technique is used to investigate the integration of the hard bio-composite cement in cortical bone defect. The induced bone defect was filled by the bio-composite paste and the bone is immersed in deionized water at $37^{\circ} \mathrm{C}$ $(\mathrm{pH}=6.8)$. After five days of maturation, the sample (bone with hard bio-composite cement) is dried and analyzed by X-ray Scanner (EasyTom XL duo). The pixel size was determined at $33.51 \mu \mathrm{m}$ under rotation with the following conditions: $90 \mathrm{kV}$ and $250 \mathrm{~mA}$.
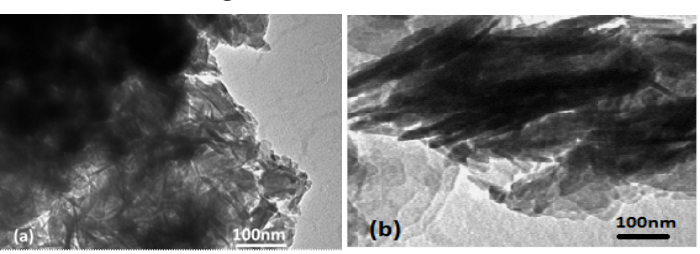

Fig. 3. TEM micrographs of the cement sample (a) and biocomposite cement (b) after five days of maturation at $37^{\circ} \mathrm{C}$ in deionized water 
The reconstructed images are processed with XAct (RX solution) software then computational image processing is applied on them. The result shows that the hard bio-composite cement is radiopaque with a homogenous porous microstructure and intimate contact bone/implant (Fig. 4). The size variation of pores, determined by processing the obtained images, is ranging from 40 to $400 \mu \mathrm{m}$.

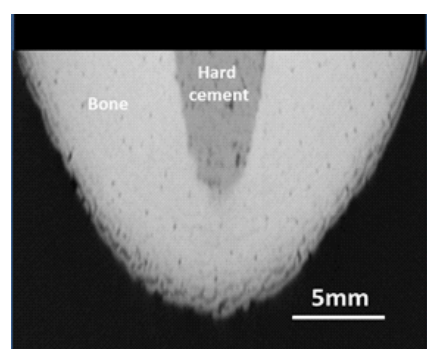

Fig. 4. X-ray scanner image of hard composite apatite/ chitosan cement in bone cavity. Image obtained after applying computational image processing

\section{Results of antibacterial tests}

The antibacterial tests are performed on cement after maturation of five days in water at $37{ }^{\circ} \mathrm{C}$. Table 1 presents the CFU enumeration per cement pellet after $72 \mathrm{~h}$ of incubation with $S$. aureus and $S$. epidermidis. For both tested strains of staphylococci, a dramatical decrease has been observed in bacterial numeration (anti-adhesion and anti-biofilm formation effect). The cements loaded with $1 \mathrm{wt} \%$ and 2 wt $\%$ chitosan induce lower colonization of these bacteria on the surface of the cement. However, these percentages haven't really a synergistic effect on the antimicrobial properties of chitosan. The cement loaded with $3.5 \mathrm{wt} \%$ of chitosan has elevated mortality of $S$. epidermidis strains and completely inhibit $S$. aureus formation on the cement surface. The values presented in Table 1 are derived from the average of 3 tests for each preparation.

\section{DISCUSSION}

\section{Physicochemical evolution of prepared cement}

Regardless of the amount of chitosan, the appearance of prepared cement shows a similarity. Once the powder is mixed with the liquid phase, the mixture becomes a malleable paste. This paste sets then hardens without disintegration after immersion in water at $37^{\circ} \mathrm{C}$. However when the amount of chitosan increases, the viscosity of the liquid phase increases and the plasticity of the prepared paste increases. The setting time of the cement without chitosan is averagely 45 minutes. At the highest concentration of chitosan setting time becomes 30 minute.

The setting of calcium phosphate cement is usually due to the formation of more hydrated constituents than the initial one. In the case of $\mathrm{CaHPO}_{4}, 2 \mathrm{H}_{2} \mathrm{O} / \mathrm{Ca}(\mathrm{OH})_{2}$ mixture, the dissolution of the reagents (Eq. (1,2 and 3)) induces the formation of calcium phosphate germs. The $\mathrm{pH}$ value of the mixture was initially 12.8 decreased to 10 after 45 minute. The nuclei formed in alkaline medium promote the precipitation of the hydrated phase with formula: $\mathrm{Ca}_{3 \mathrm{n}}\left(\mathrm{PO}_{4}\right)_{2 n}, \mathrm{H}_{2} \mathrm{O}$ (TCPh) (Eq. (4) ${ }^{26}$. The setting of cement is due to the formation of this hydrated-tricalcium phosphate which is transformed quickly into calcium-apatite structure $\left(_{\mathrm{Ca}+\mathrm{Y}}\left(\mathrm{PO}_{4}\right)_{6}\right.$ $(\mathrm{OH})_{2 y} 0<\mathrm{y}<1$ : ACPap (Eq. (5)).

Table 1: Evaluation of antibacterial activity of cement with and without chitosan in the presence of two bacteria (S. aureus and S. epidermidis)

\begin{tabular}{|c|c|c|c|c|}
\hline \multirow[b]{2}{*}{$\begin{array}{l}\text { Chitosan in apatite } \\
\text { cement (Wt \%) }\end{array}$} & \multicolumn{2}{|c|}{ S. epidermidis } & \multicolumn{2}{|c|}{ S. aureus } \\
\hline & $\begin{array}{l}\text { CFUs } / \mathrm{cm}^{2} \text { in } \\
\text { stock solution }\end{array}$ & $\begin{array}{l}\text { CFUs/cm² in } \\
\text { diluted solution }\end{array}$ & $\begin{array}{l}\text { CFUs } / \mathrm{cm}^{2} \text { in } \\
\text { stock solution }\end{array}$ & $\begin{array}{l}\text { CFUs } / \mathrm{cm}^{2} \text { in } \\
\text { diluted solution }\end{array}$ \\
\hline 0 & 168 & 90 & 32 & 4 \\
\hline 1 & 36 & 24 & 25 & 2 \\
\hline 2 & 28 & 18 & 15 & 0 \\
\hline 3.5 & 24 & 13 & 0 & 0 \\
\hline
\end{tabular}

$$
\begin{aligned}
& \mathrm{Ca}(\mathrm{OH})_{2} \rightarrow \mathrm{Ca}^{2+}+2\left(\mathrm{OH}^{-}\right) \\
& (\mathrm{Eq} 1) \quad \mathrm{Ca}_{9}\left(\mathrm{PO}_{4}\right)_{6}, \mathrm{nH}_{2} \mathrm{O}+\mathrm{y} \mathrm{Ca}{ }^{2+}+2 \mathrm{yOH} \rightarrow\left(\mathrm{Ca}_{9+\mathrm{Y}}\left(\mathrm{PO}_{4}\right)_{6}(\mathrm{OH})_{2 \mathrm{y}}\right. \\
& \mathrm{CaHPO}_{4}, 2 \mathrm{H}_{2} \mathrm{O} \rightarrow \mathrm{Ca}^{2+}+\mathrm{HPO}_{4}{ }_{4}^{2-}+\mathrm{H}_{2} \mathrm{O} \\
& \text { (Eq 2) } 0<\mathrm{y}<1: \text { (ACPap) } \\
& \text { (Eq 5) } \\
& \mathrm{HPO}_{4}{ }^{2-}+\mathrm{OH}^{-} \rightarrow \mathrm{PO}_{4}{ }^{3-}+\mathrm{H}_{2} \mathrm{O} \\
& \text { (Eq 3) } \quad \mathrm{Ca}_{9+\mathrm{Y}}\left(\mathrm{PO}_{4}\right)_{6}(\mathrm{OH})_{2 \mathrm{y}} \mathrm{CO}_{3}{ }^{2-} \rightarrow \mathrm{Ca} 9+\mathrm{Y}\left(\mathrm{PO}_{4}, \mathrm{CO}_{3}\right)_{6}(\mathrm{OH})_{2 y} \\
& 9 \mathrm{Ca}^{2+}+6 \mathrm{PO}_{4}{ }^{3-}+\mathrm{nH}_{2} \mathrm{O} \rightarrow \mathrm{Ca}_{9}\left(\mathrm{PO}_{4}\right)_{6}, \mathrm{nH}_{2} \mathrm{O}(\mathrm{TCPh}) \\
& \text { : (ACPcap) }
\end{aligned}
$$


The alkalin medium promotes the insertion of carbonate ions of the air and favors the formation of carbonated apatite as shown by the IR analyzes (Fig $2 \mathrm{~b})$. The radical phosphate $\left(\mathrm{PO}_{4}^{3-}\right)$ can partially be replaced by a radical carbonate $\left(\mathrm{CO}_{3}{ }^{2-}\right)(\mathrm{Eq} 6)$.

The microstructure of the final product (entangled needles) leads to the hardness of cement. Thus, the apatite formed is similar to the bone mineral in its composition and structure. The bones and teeth of all vertebrates are formed by carbonate-hydroxyapatite.

The same process is observed in the case of the preparation in the presence of chitosan but with slight inhibition in the evolution towards the apatite phase.

The short setting time (30 min.) in the case of bio-composite is not due to the formation of hydrated tricalcium phosphate but to the chitosan precipitation, which strengthens the cohesion between grains and increases the viscosity of the paste. Indeed, the chitosan is brought by the acid solution it is thus positively charged; the intensity of this load is determined by the number of free functions amines, characterized by the degree of deacetylation ( $\mathrm{DD}=78 \pm 2 \%$ in our case). The $-\mathrm{NH}_{3}{ }^{+}$ group allows the chitosan to be solubilized in the acid solution. The addition of the acid solution (acid lactic/ chitosane) in the basic calcium phosphate powder, leads then to the precipitation of chitosan according to the balance of dissociation (Eq 7).

The $-\mathrm{NH}_{2}$ group confers good chelating properties of amino grouping with calcium hydrogenophosphate according to the (Eq 8). The adsorption of the polymer on the surface of dicalcium phosphate crystals induces a slight inhibition of dissolution rate of DCPD.

Due to a large number of $-\mathrm{OH}^{-}$and $-\mathrm{NH}_{2}$ groups, chitosan can easily chelates with metal ions. The slow evolution of the cement therefore can be attributed also to chelation of calcium ions (Eq 9) which leads to an inhibition of the precipitation of the apatite phase $\mathrm{e}^{23,27}$.

$$
\begin{array}{ll}
\mathrm{R}-\mathrm{NH}_{3}{ }^{+}+\mathrm{H}_{2} \mathrm{O}<==>\mathrm{R}-\mathrm{NH}_{2}+\mathrm{H}_{3} \mathrm{O}^{+} & (\mathrm{Eq} \mathrm{7}) \\
\mathrm{R}-\mathrm{NH}_{2}+-\mathrm{Ca}-\mathrm{HPO}_{4}^{-}<==>\mathrm{R}^{+} \mathrm{NH}_{2}-\mathrm{Ca}-\mathrm{HPO}_{4}^{-} & (\mathrm{Eq} 8) \\
\mathrm{R}-\mathrm{NH}_{2}+-\mathrm{Ca}-\mathrm{O}-\mathrm{H}-<==>\mathrm{R}-\mathrm{NH}_{2}-\mathrm{Ca}-\mathrm{O}-\mathrm{H} & (\mathrm{Eq} \mathrm{9)}
\end{array}
$$

We can conclude that after mixing the solid and liquid phases of cement, the components turn into a malleable paste without disintegration after immersion in water at $37^{\circ} \mathrm{C}$. The hardening of paste is caused by formation of hydrated tricalcium phosphate and the hardness is caused by formation of Calcium apatite crystallized as needle-like entangled. In the presence of chitosan, the viscosity of the liquid phase increases more and the plasticity of the paste increases that strengthens the cohesion between grains and promotes rapid-hardening of cement paste.

Chemical interaction between $-\mathrm{Ca}^{2+}$ ions and $-\mathrm{OH}$ - groups of apatite and $-\mathrm{NH}_{2}$ or $-\mathrm{OH}$ groups of chitosan slightly inhibits the evolution towards well crystallized apatite phase.

The incorporation of apatite particle in the chitosan matrix by in situ nucleation would provide homogenous distribution and also improve the mechanical strength of the composite compared to simple mixing of hydroxyapatite in chitosan. More important, the result of X-ray scanner technique shows the perfect integration of the prepared bio-composite cement in the bone structure and total connectivity bone/composite. The hard bio-composite cement is radiopaque and has a homogenous porous microstructure. The microstructure, the composition and the perfect integration in the bone cavity, affect positively the desired biological properties of the bio-composite cement such as stability and resorbability.

\section{Antibacterial tests}

The results of antibacterial test demonstrate that the effect of chitosan is different on the both bacteria: S. aureus and S. epidermidis. These both bacteria are distinct in their structures, the first is coagulase positive staphylococci (CPS) and the second is coagulase-negative staphylococci (CNS). The chitosan shows higher antibacterial activity for S. aureus (CPS) than for the S. epidermidis.

The antimicrobial mechanism of chitosan was proposed by various authors. In fact, chitosan leads to a distortion of cell membranes of strains. 
This eliminates any exchange between the bacteria and nutrient external environment ${ }^{28}$.

The antibacterial action of chitosan was also explained by Gilbert P. and $\mathrm{al}^{29}$, they reported that chitosan is absorbed into the bacterial cell and interacts with the phospholipids of bacteria. Chitosan acts on proteins exposed only to the cell surface of the $S$. aureus strains that have the ability to bind to the cement. This causes a disruption of the cytoplasmic membrane and lysis of protoplasts for this strain. The degradation of proteins and nucleic leads to a disturbance of the cell structure with a loss of membrane integrity for PCS strains (S. aureus). These mechanisms may therefore explain the difference in the action of chitosan on both bacteria.

Other factors may also influence the antibacterial activity of chitosan for example: the physicochemical characteristics of chitosan, its physical state and environmental conditions $(\mathrm{pH} \text {, temperature and metal ions })^{30,31}$.

The degree of deacetylation of the chitosan is related to its positive charge density. However, a high positive charge density provides strong antibacterial activity to chitosan ${ }^{31-33}$. Indeed, due to the process of acidification of the extracellular environment of osteoclasts in an acid environment, the $-\mathrm{NH}^{3+}$ group leads to the formation of binding chitosan-phospholipid of bacteria cell membrane with negative charge, thus distorting the tradeoff between the microbial cells and the external environment ${ }^{34-39}$.

The average molecular weight of chitosan can also influence its antibacterial effect. Some studies have shown that increasing the molecular weight, the antibacterial effect of chitosan decreases, others showed the opposite result ${ }^{40,41}$. This result may be related to the conformation and to the free charge density of each polymer. Antibacterial activity of chitosan can therefore include several mechanisms strongly depending on the charge density in the interacting components.

\section{CONCLUSION}

This work concerns the development of bone and tooth composite cement with properties that meet to the expectations of practitioners, namely an easy preparation, an evolution to apatite calcium phosphate similar to mineral bone which promotes an optimal integration into the implanted site and a good antibacterial activity. The prepared cement, from mixture of $\mathrm{CaHPO}_{4}, 2 \mathrm{H}_{2} \mathrm{O} / \mathrm{Ca}(\mathrm{OH})_{2} /$ Chitosan leads to a malleable paste that sets to a firm mass without disintegration in water. The hardening process is caused by formation of hydrated tricalcium phosphate and the hardness is caused by formation of Calcium-apatite crystallized as entangled needle. The chitosan strengthens the cohesion between grains, slightly inhibits the evolution of cement and leads to the formation of rapid-hardening cement. The bio-composite cement has elevated mortality of $S$. epidermidis strains and completely inhibits the formation of $\mathrm{S}$. aureus to the cement surface. The results show that the apatite/chitosan composite prepared by the way of cements can have interesting applications in the medical field.

\section{ACKNOWLEDGMENT}

The biological study of this work was carried out by the help of the Molecular Bacteriology Laboratory of Pasteur Institute in Morocco Casablanca. We gratedully acknowledge them for technical assistance.

\section{REFERENCES}

1. Epple, M. ; Ganesan, K. ; Heumann, R.; Klesing, J.; Kovtun, A. ; Neumann, S. ; Sokolova , V. J. Mater. Chem., 2010, 20, 18-23.

2. Ginebra, MP. ; Canal, C. ; Espanol, M. ; Pastorino, D.; Montufar, EB. Advanced Drug Delivery Reviews., 2012, 64,1090-1110.

3. Tofighi, A. Key Engineering Materials., 2011, 493-494, 349-354.
4. Verron, E. ; Khairoun, I. ; Guicheux, J. ; Bouler ; Advanced Drug Delivery Reviews., 2010, 15547-552.

5. Lacout . J.L.; Hatim, Z. ; Freche, M. Patent US 6521264 B1, 2003.

6. Brown, W.E. ; Chow , L.C. American Ceramic Society: Westerville, OH, USA., 1986, 21, 351-379. 
7. Campoccia, D. ; Montanaro, L. ; Arciola , C. R. Biomaterials., 2006, 27(11):2331-9.

8. Montanaro, L. ; Speziale, P. ; Campoccia, D. ; Ravaioli, S. ; Cangini , I. ; Pietrocola, G. ; Giannini , S. ; Arciola, C. R. Future Microbiology., 2011, 6, 11.

9. Ghosh, S. ; Wu, V. ; Pernal, S. ; Uskokovic, V. ACS Appl Mater Interfaces., 2016, 8-12 7691-7708.

10. Migaud, H. ; Senneville, E. ; Gougeon, F. ; Marchetti, E. ; Amzallag, M. ; Laffargue, P. ; EMC Rhumatologie Orthopédie., 2005, 2(2) 151-172.

11. Sugawara, A. ; Asaoka, K. ; Ding, S.-J. ; Journal of Materials Chemistry., 2013, 1, 8, 1081.

12. Joosten, U. ; Joist, A. ; Frebel, T. ; Brandt, B. ; Diederichs, S. ; Von Eiff, C. ; Biomaterials, 2004, 25(18), 4287-95.

13. Hesaraki , S.; Nemati, R. ; Journal of Biomedical Materials Research., 2009, 89(2), 342-52.

14. Sasaki, T.; Ishibashi, Y. ; Katano, H. ; Nagumo, A. ; Toh, S. ; The Journal of arthroplasty., 2005 20(8). 1055-9.

15. Jiang, P.J. ; Patel, S.; Gbureck Caley, R. ; Grover, L.M.; Journal of Biomedical Materials Research. Part B: Applied biomaterials. 2010, 93(1), 51-8.

16. Feng, Q.L. ; Wu, J. ; Chen, G.Q. ; Cui, F.Z ; Kim, T.N.; Kim J.O. ; Journal of Biomedical Materials Research., 2000, 52(4), 662-8.

17. Venkaesan, J. ; Kim, Se-K. ; Journal Mar Drugs., 2010, 8(8), 252-2266.

18. Li, Z. ; Yubao, L. ; Aiping, Y. ; Xuelin, P. ; Xuejiang, W. ; Xiang, Z. ; J. Mater. Sci. Mater. Med., 2005, 16, 213-219.

19. Cheng, X. ; Li, Y. ;Zuo, Y. ;Zhang, L. ; Li, J. ; Mater Sci Eng C Mater Biol Appl., 2009, 29, 29-35.

20. Venkatesan, J.; Lee, J-Y. ; Kang, D. S. ; Sukumaran, A. ; Kim, M. ; Shim, S. ; Kim, D. G. ; International Journal of Biological Macromolecules., 2017, 98, 515-525.

21. Foster, LJR.; Ho, S. ; Hook, J.;Basuki, M. ; Marçal, H. ; PLOS ONE., 2015, 10(8), 0135153.

22. Yamaguchi, I. ; Tokuchi, K. ; Fukuzaki, H.; Koyama, Y. ; Takakuda, K.; Key Eng Mater., 2000, 4, 192-195.

23. Leroux, L.; Hatim, Z. ; Freche, M. ; Lacout, J.L; Bone., 1999, 25(2), 31S-34S.
24. Rey, C. ; Combes, C. ; Drouet, C. ; Sfihi, H. ; Adv. Sci. Technol., 2006, 49, 27-36.

25. Abida, F. ; Elassfouri, M. ; Ilou, M. ; El ouatli, B. ; Jamil, M. ; Moncif , N. ; Hatim, Z.; Mediterranean Journal of Chemistry., 2017, 6(3), 71-76.

26. Combes, C. ; Rey, C. ; Acta Biomaterialia., 2010, 6(9), 3362-3378.

27. Abida, F. ; Elouahli, A.; Bourouisse, A.; Jamil, M.; Gourri, ELH.; Ezzahmouly, M.; Hatim , Z.; $J$ of Scientific \& Engineering Research., 2016 $7(5), 28-33$.

28. A.Muzzareli, R. A. ; Muzzarelli, C. ; Tarsi, R.; Miliani, M.; Gabbanelli, F.; Cartolari, M.; Biomacromolecules., 2001, 2, 165-169.

29. Gilbert, P. ; Moore, LE. ; J Appl Microbiology., 2005, 99, 703-715.

30. Kong, M.; Chen, X. G. ; Xing, K. ; J. Park, H. ; International Journal of Food Microbiology., 2010, 144(1), 51-63.

31. Erdem, B. ; Kariptas, E.; Kaya, T. ; Tulumoglu, S ; Gorgulu,; International Current Pharmaceutical Journal., 2016, 5(5), 45-48.

32. Kong, M. ; Chen, X. ; Xue, Y. ; Liu, C.; $\mathrm{L}-\mathrm{J} \mathrm{Yu}$; Frontiers of Materials Science in China., 2008, 2(2), 214-220.

33. Takahashi, T. ; Imai, M.; Suzuki, I. ; Sawai, J. Biochemical Engineering Journal., 2008, 40(3), 485- 491.

34. Bégin, A. ; Calsteren, M. V. ; International Journal of Biological Macromolecules., 1999, 26, 63-67.

35. Liu, X. F.; Guan, Y. L. ; Yang, D. Z. ;. Li, Z ; Yao, K. D.; Journal of Applied Polymer Science., 2001, 79, 1324-1335.

36. Devlieghere, F.; Vermeulen, A.; Debevere, J.; Microbilogy., 2004, 21, 703-714.

37. Qin, C. ; Li, H.; Xiao, Q.; Liu, Y. ; Zhu, J. ; Du, Y. ; Carbohydrates Polymers., 2005, 63, 367-374.

38. Peng, Y.; Han, B. ; Liu, W. ; Xu, X.; Carbohydrate research., 2005, 340, 1846-1851.

39. Yang, T. S. ; Chou, C. C. ; Li, C. F. ; International Journal of Food Microbiology., 2005, 97, 237-245.

40. Tikhonov, V. E. ; Stepnova, E. A. ; Babak, V. G. ; Jansson, I. A. ; Carbohydrate Polymers., 2006, 64(1), 66-72.

41. Tokura, S. ; Ueno, K. ; Miyazaki, S. ; Nishi, N. ; Macromolecular Symposia., 1997, 120(1), 1-9. 